\title{
World Mental Health Day, Mental Health for All - October 10, 2020
}

\author{
$\operatorname{Lin~} \mathrm{Lu}^{*}$
}

\begin{abstract}
World Mental Health Day was initiated in 1992 by the World Federation for Mental Health (WFMH), a global mental health organization with members and contacts in more than 150 countries, and is celebrated every year to educate people on mental health, raise awareness for mental illnesses, and reduce associated stigma. It is supported by the World Health Organization (WHO) based on its strong relationships with ministries of health and civil society organizations across the globe.

Mental health refers to cognitive, behavioral, and emotional wellbeing and is important at every stage of life from childhood and adolescence through adulthood to old age. However, mental health issues have increased significantly over the last several decades as the burden of mental disorders grows with significant impacts on health and major social and economic consequences. With over 970.8 million people suffering from mental disorders worldwide, mental disorders have consistently accounted for more than $14 \%$ of age-standardized years lived with disability for the last 30 years (1), and the prevalence reached $22.1 \%$ in conflict-affected populations (2). With unprecedented economic development and social change in the past 3 decades in China, Chinese people are experiencing great psychological pressure and stress and have a lifetime prevalence of mental disorders at $16.6 \%$ (3).

Examples of mental illness include depressive disorders, anxiety disorders, schizophrenia, eating disorders, autism spectrum disorders, etc., and they are generally characterized by a combination of abnormal thoughts, perceptions, emotions, behaviors, and social relationships. Untreated mental illness causes emotional, behavioral, and physical health problems and can even result in severe or fatal outcomes like suicide. According to the WHO, 1 person dies by suicide every 40 seconds in the world, and most suicides are related to mental illness. Thus, the World Mental Health Day 2019 focused on suicide prevention with the theme "Mental Health Promotion and Suicide Prevention".
\end{abstract}

In 2020, people of the world are facing the unprecedented impact of the coronavirus disease 2019 (COVID-19) pandemic, which has caused serious threats to physical and mental health. As the world struggles to bring the pandemic under control, social distancing and emotional distress have become widespread. Mental health symptoms including depression, anxiety, insomnia, and acute stress have increased during the COVID-19 pandemic among the general population, especially among infected individuals, people with suspected infection, and people who might have had contact with COVID-19 patients (4-5).

The theme of World Mental Health Day 2020 is "Mental Health for All: Greater Investment — Greater Access." Under the challenges brought by the COVID-19 pandemic to mental health, guaranteeing health equity for everyone is critically important. The Chinese government has implemented a series of rapid and comprehensive public health emergency interventions to strengthen the mental healthcare system and increase the availabilities of mental healthcare services. We hope that the World Mental Health Day 2020 will be accompanied by united efforts from countries, societies, governments, and organizations to achieve improvements in mental health equity and accessibility for all.

doi: $10.46234 / \mathrm{ccdcw} 2020.216$

\# Corresponding author: Lin Lu, linlu@bjmu.edu.cn.

Submitted: September 22, 2020; Accepted: September 23, 2020

\section{REFERENCES}

1. GBD 2017 Disease and Injury Incidence and Prevalence Collaborators. Global, regional, and national incidence, prevalence, and years lived with disability 
for 354 diseases and injuries for 195 countries and territories, 1990-2017: a systematic analysis for the Global Burden of Disease Study 2017. Lancet 2018;392(10159):1789 - 858. http://dx.doi.org/10.1016/s0140-6736(18)32279-7.

2. Charlson F, Van Ommeren M, Flaxman A, Cornett J, Whiteford H, Saxena S. New WHO prevalence estimates of mental disorders in conflict settings: a systematic review and meta-analysis. Lancet 2019;394(10194):240 - 8. http://dx.doi.org/10.1016/s0140-6736(19)30934-1.

3. Huang YQ, Wang Y, Wang H, Liu ZR, Yu X, Yan J, et al. Prevalence of mental disorders in China: a cross-sectional epidemiological study. Lancet Psychiatry 2019;6(3):211 - 24. http://dx.doi.org/10.1016/s2215-0366(18)30511-x.

4. Bao YP, Sun YK, Meng SQ, Shi J, Lu L. 2019-nCoV epidemic: address mental health care to empower society. Lancet 2020;395(10224):e37-8. http://dx.doi.org/10.1016/s0140-6736(20)30309-3.

5. Shi L, Lu ZA, Que JY, Huang XL, Liu L, Ran MS, et al. Prevalence of and risk factors associated with mental health symptoms among the general population in China during the coronavirus disease 2019 pandemic. JAMA Netw Open 2020;3(7):e2014053. http://dx.doi.org/10.1001/jamanetworkopen. 2020.14053.

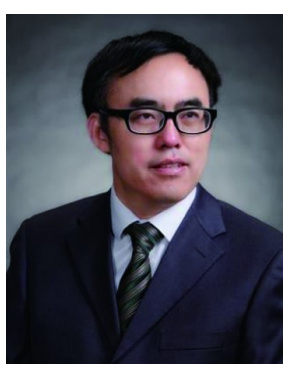

Lin Lu, M.D., Ph.D.

Academician, Chinese Academy of Sciences

Director/Professor, Peking University Sixth Hospital/Institute of Mental Health, Peking University

Director/Professor, National Clinical Research Center for Mental Disorders

Director/Professor, National Center for Mental Health, China CDC 